\title{
Psychosocial Determinants of Family Planning in Tigrai National Regional State, Ethiopia
}

\author{
Teklebrhan Berhe
}

\author{
Department of Psychology, Adigrat University, Tigrai, Ethiopia P.O Box 50
}

\begin{abstract}
The purpose of the study is to find out the psychosocial determinants or predictors that may affect family planning decision and use in Tigrai National Regional State. Data were collected through a structured questionnaire from women married at the time of survey. Interview was carried out for a total of 600 women age 15- 49. An analytical study was done to find the association between unmet needs and the explanatory variables using binary logit model. Result of this study indicated that, clients chose family planning methods basing on few options given as most of health centers' family planning providers sampled were biased towards the three most commonly used methods, depoprovera, pills and condoms respectively. Low utilization of modern contraception despite a near universal awareness through various forums confirms that the women need more knowledge on FP methods that will focus on available options and their effects on health. Women who discussed choice and use of contraceptive method were more likely to use compared to those who did not. Based on the results, it can be recommend that reproductive health programs need to intensify efforts in improving women's knowledge of modern FP methods. They should also encourage constructive partner communication and engagement in order to increase modern FP uptake. There is also need to re-evaluate the current integrated maternal child health and family planning services to directly, actively and effectively accommodate male partners. Further research into the male partner views on family planning; psychosocial and cultural determinants of non-use; and barriers to the use of modern contraceptive methods among both men and women are proposed. The family planning program at national level in conjunction with the District/woreda Health Offices should intensify supervision of family planning activities to ensure that providers are performing according to the set standards of family planning. Health centers should be provided with the National Reproductive Health (NRH) service delivery guidelines and policy to be used as a basis of their family planning service provision. In charge of health center should ensure that Ethiopian NRH and policy handbooks are always available in the FP clinic for easy access
\end{abstract}

Keywords: Psychosocial, Determinants and Family planning.

\section{Introduction}

Family planning can be defined as the ability of individuals and couples to anticipate and attain their desired number (IUD of children and the spacing of and timing of their births (FDRE, MoH, 2011), injectables, implants, male and female condoms, diaphragm and emergency contraception are modern methods of contraception. Similarly, traditional methods include periodic abstinence, withdrawal and folk methods. It is required for individuals and couples to anticipate and attain their desired number of children and also for the spacing and timing of their births. It has direct impact on women's health and well-being as well as on the outcome of each pregnancy. It is also one of the most costeffective interventions available (Saha, K. B., N. Singh, et al., 2007).

Family planning services in Ethiopia was started in 1966 by The Family Guidance Association of Ethiopia, a nongovernmental organization. In 1975, the Ethiopian government started integrating family planning with maternal and child health services. After the adoption of the population policy in 1993, a number of other stakeholders have been involved in family planning promotion.

According to the Ethiopian Demographic and Health Survey (EDHS), between 1990 and 2011, total fertility in Ethiopia declined from 6.4 to 4.8 births per woman (CSA 2012a). Furthermore, the use of contraceptive methods among women in union or those who are sexually active has increased nearly six fold in the last 11 years, from 7 percent in 2000 to 14 percent in 2005 to 28 percent in 2011 (CSA 2001a, 2006a, 2012a). These are significant achievements by any standard, though the current fertility rate and unmet need for family planning still remain high. Further, population growth remains around 2.6 percent annually, making Ethiopia Africa's second-most-populous country with an estimated population of 88 million in 2011 (US Census, 2013).

Ethiopia has among the highest levels of unmet need for contraception in Africa. The 2011 Ethiopia Demographic and Health survey (EDHS) found that $25.3 \%$ of women had unmet need for FP, $16.3 \%$ for spacing and $9 \%$ for limiting. Unmet need for both spacing and limiting is higher among rural residents than their urban counter parts. An Ethiopian woman bears an average of five children in her lifetime. As of 2011, 29 percent of married Ethiopian women of childbearing age (15-49) use any method of family planning; this is a dramatic increase from 2005-when only 15 percent of married women of childbearing age were using any form of contraception. However, 25 percent of married women do not want any more children or want to wait for two or more years before having another child but are not currently using any form of contraception. Family planning efforts need to expand to address this -unmet need" for family planning-particularly among young women ages 15-19 that have the highest unmet need (33\%) (Ha, B. T., R Jayasuriya, et al,. 2005).

A proper understanding of the extent of unmet need for FP among currently married women of reproductive age and associated factors are of paramount importance in tackling the problem of unmet need for FP, which paves the way for the improvement of the prevailing socioeconomic problems of the country in general and the region in particular. The 


\section{International Journal of Science and Research (IJSR) \\ ISSN (Online): 2319-7064 \\ Index Copernicus Value (2013): 6.14 | Impact Factor (2015): 6.391}

overall objective of this study is therefore to find out the psychosocial determinants or predictors that may affect family planning decision and use in Tigrai National Regional State.

\section{Materials and Methods}

\section{Study Area Description}

Tigrai is one of the nine regions of the Federal Democratic Republic of Ethiopia which lies in the North tip of Ethiopia, extending from $12^{0} 15^{\prime}$ to $14^{0} 54^{\prime}$ North and $36^{\circ} 27^{\prime}$ to $39^{0}$ 59' East. The region is bordered by Eritrea to the north, Sudan to the west,Afar regional state to the east and the Amhara region to the South.

\section{Method of Data Analysis}

Both descriptive statistics and econometric models wereemployed to analyse the data. Descriptive statistics like mean, frequency, percentages, etc and Econometric models through Statistical Package for Social Science (SPSS) and STATA were employed.

\section{Model Specification}

Binary logistic regression was employed to analyze the unmet needs of family planning at the household level. The dependent variable (dichotomous variable) will assume two values (Unmet need to space and unmet need to limit was recorded as $1=y e s$ and other responses including missing value was recorded as $0=$ No.) and the independent variables will assume any value, both continuous and categorical variables. Hence, a binary dependent variable logit model following Gujarati (1988) is specified as below and was used.

$$
P\left(Y_{i}=1\right)=\frac{e^{\alpha+\beta X_{i}}}{1+e^{\alpha+\beta X_{i}}}
$$

Where: $\mathrm{Yi}$ is $\mathrm{i}^{\text {th }}$ observation response who has two outcomes (Unmet need to space and unmet need to limit was recorded as $1=y e s$ and other responses including missing value was recorded as $0=$ No.)

$\mathrm{X}_{\mathrm{i}}=$ are factors that affect household's unmet needs for family planning,

$\alpha=$ the constant term and $\beta$ 'sare the coefficient of the variables (vector of parameters to be estimated).

The model that will be used by this study to determine factors affecting unmet needs of family planning is given below:

$$
\pi(X)=\frac{1}{1+\mathrm{e}^{-(\beta 0+\beta \mathrm{i} X \mathrm{i} i)}}
$$

the above equation can be written as:

$$
\pi(X)=\frac{1}{1+\mathrm{e}^{-\mathrm{Zi}_{1}}}
$$

Where $\Pi(\mathrm{x})=$ the probability of household being unmet needs of family planning

$\mathrm{Zi}=\beta \mathrm{o}+\beta 1 \mathrm{X} 1+\beta 2 \mathrm{X} 2+$ $+\beta n X n$

$\beta o=$ is an intercept

$\beta 1, \beta 2 \ldots \beta n$ are slopes of the equation

$\mathrm{Xi}=$ explanatory variables it represents independent variables
The probability of unmet needs of family planning is given by equation (02).

Similarly, the probability for being a met need of family planning is:

$$
1-\pi(X)=\frac{1}{1+\mathrm{e}^{Z_{1}}}
$$

Thus, it can be writtenthe two equations ([02], \& [03]) together as

$$
\frac{\pi(X)}{1-\pi(X)}=\frac{1+\mathrm{e}^{Z_{1}}}{1+\mathrm{e}^{-Z_{1}}}
$$

$=\mathrm{e}^{\mathrm{Zi}}$

Then, $\pi(X)$ is simply the odds ratio of unmet needs of

$$
\overline{1-\pi(X)}
$$

family planning

Finally, by taking the natural log of equation (04) it can be obtained:

$$
\mathrm{Li}=\frac{\ln \pi(X)}{1|-\pi(X)|}=\mathrm{Zi}
$$

Where, $\mathrm{Zi}=\beta \mathrm{o}+\beta 1 \mathrm{X} 1+\beta 2 \mathrm{X} 2+$ $+\beta n X n$

If the disturbance term (Ui) is interoduced, the logit model becomes

$$
\mathrm{Zi}=\beta \mathrm{o}+\beta 1 \mathrm{X} 1+\beta 2 \mathrm{X} 2+
$$$$
+\beta n X n+U i
$$

Where $\mathrm{Li}$ is the odds ratio, which is not only linear in $\mathrm{Xi}$ but also linear in parameters and $\mathrm{Xi}$ is the vector of explanatory variable.

Independent variables

Age, Place of residence ( $1=$ urban, $0=$ rural), Religion, Education, Wealth index, Parity, Age at first marriage, media exposure among others

\section{Results and Discussion}

\section{Family planning method specific information by zonal health centers}

Results of observation indicated that clients from Mekelle, Eastern and Centralzone health centers got almost all details concerning fertility awareness method, spermicides, and permanent contraception. The information included mode of action, advantages, disadvantages, side effects, side effect management, possible problems and STI/ HIV protection. Southern and western zone health centers gave only some information on mode of action and effectiveness of spermicides and permanent contraception while North western provided information on mode of action of permanent contraception only.

Awareness and practices of women and their families about contraceptives 


\section{International Journal of Science and Research (IJSR) ISSN (Online): 2319-7064 \\ Index Copernicus Value (2013): 6.14 | Impact Factor (2015): 6.391}

Table: Percentage of currently married women aged 15-49 currently using any contraceptive method by selected demographic and socioeconomic characteristics,

\begin{tabular}{|c|c|c|}
\hline Characteristic & $\begin{array}{l}\text { No. of } \\
\text { women }\end{array}$ & $\begin{array}{l}\text { \% currently using } \\
\text { contraception }\end{array}$ \\
\hline \multicolumn{3}{|l|}{ Age of respondent (years) } \\
\hline $15-25$ & 128 & 9.6 \\
\hline $25-35$ & 345 & 28.7 \\
\hline $35-49$ & 127 & 37.1 \\
\hline \multicolumn{3}{|l|}{ No. of living children } \\
\hline 0 & 108 & 11.8 \\
\hline 1 & 57 & 17.4 \\
\hline 2 & 206 & 15.3 \\
\hline 3 & 265 & 25.3 \\
\hline $4+$ & 36 & 15.8 \\
\hline \multicolumn{3}{|l|}{ Marital duration (years) } \\
\hline$<5$ & 354 & 22.5 \\
\hline 10-May & 172 & 35.4 \\
\hline $10+$ & 74 & 28.3 \\
\hline \multicolumn{3}{|l|}{ Woman's education } \\
\hline None & 234 & 6.7 \\
\hline Primary & 290 & 10.3 \\
\hline Secondary & 51 & 21.4 \\
\hline Tertiary & 25 & 26.1 \\
\hline \multicolumn{3}{|l|}{\begin{tabular}{|l|} 
Husband's education \\
\end{tabular}} \\
\hline None & 125 & 15.05 \\
\hline Primary & 102 & 16.3 \\
\hline Secondary & 168 & 29.65 \\
\hline Tertiary & 205 & 31.4 \\
\hline \multicolumn{3}{|l|}{ Husband's occupation } \\
\hline Never worked & 25 & 14.5 \\
\hline Professional & 357 & 33.4 \\
\hline Trader & 145 & 12.4 \\
\hline Skilled and unskilled worker & 73 & 11.8 \\
\hline \multicolumn{3}{|l|}{ Religion } \\
\hline Orthodox & 429 & 13.7 \\
\hline Catholic & 123 & 18.4 \\
\hline Muslim & 48 & 11.8 \\
\hline \multicolumn{3}{|l|}{ Desire for more children } \\
\hline Want more & 523 & 9.92 \\
\hline Want no more & 73 & 26.65 \\
\hline \multicolumn{3}{|l|}{ Husband approves FP } \\
\hline Disapproves & 114 & 6.2 \\
\hline Approves & 365 & 25.34 \\
\hline Don’t know & 121 & 19.54 \\
\hline \multicolumn{3}{|l|}{ Discussed FP with partner } \\
\hline Never & 68 & 7.5 \\
\hline Once or twice & 82 & 16.64 \\
\hline More often & 450 & 27.85 \\
\hline \multicolumn{3}{|l|}{ Respondent approves FP } \\
\hline Disapproves & 106 & 1.5 \\
\hline Approves & 494 & 16.54 \\
\hline
\end{tabular}

The table above shows the percentage distribution of currently married women aged 15-49 currently using contraception by selected demographic and socioeconomic characteristics. Current use is positively associated with respondent's age, number of living children and level of education. As expected, both the respondent's and her spouse's approval of family planning promotes higher current contraceptive use. Current use is directly related to frequency of discussion of family planning with the partner. Among currently married women, $7 \%$ of those who had never discussed family planning with their partner and 30\% of those who had discussed family planning with their partner were currently using contraception.

This paper examines the relationship between selected demographic and psychosocial variables and current use of contraception. Respondent's approval of family planning, discussion of family planning with partner and level of education emerge as the most important explanatory variables. On the other hand, respondent's age, religion, desire for more children and marital duration have no significant effects on current use of contraception.

It is surprising that sociocultural variables such as religion and ethnicity do not have any significant effect on current use of contraception. A possible explanation is that, once a woman experiences higher education and religious affiliation do not significantly affect her current contraceptive use.

Respondent's approval of family planning is the most important predictor of current use of contraception. This is to be expected because respondents who approve of family planning are more likely to ensure that their favorable attitude is translated into high use of contraception.

The curvilinear relationship found between fertility and female education in Tigrai may be due in part to a relatively low level of contraceptive use among women with primary education who have largely abandoned traditional practices, such as prolonged breast-feeding and sexual taboos after childbirth, with their compensating influences on fertility.

The effects of the respondent's characteristics predominate over those of her spouse.

Husband's characteristics such as approval of contraception, level of education and occupation are insignificant when respondent's characteristics were entered into the model. In particular, husband's education has no significant effect on respondent's current contraceptive use. However, spousal consent is very important to service providers.

The relatively low fertility of women with higher education is largely attributable to a high level of contraceptive use. The findings suggest that a certain education threshold is necessary for women to use contraception. Increasing female education is not only good in itself but also for improving the status of women. Females should be given at least secondary education so as to improve the effectiveness of contraceptive use that will lead to lower fertility and better health. There is a need also for periodic analysis of family planning service delivery points to complement the supply side of the family planning equation.

Except $24.6 \%$ of the participants, all the remaining $75.4 \%$ women agreed that large family size is undesirable because it leads to poor quality of life, increased expenditures and deterioration of women's health. Meanwhile, the two study 


\section{International Journal of Science and Research (IJSR) \\ ISSN (Online): 2319-7064 \\ Index Copernicus Value (2013): 6.14 | Impact Factor (2015): 6.391}

subjects said that they never intended to limit their family size as -Iall depends on God" and - agegap of two up to three years still existed between their children without the use of any contraceptives."

97.3\%of the participants though were aware of one or more modern methods of contraception but their actual use was found to be very low among them. Condoms were ever used by $4.33 \%$ participants and were procured by their husbands. It was also observed that women resort to varied measures on their own to limit the number of births due to lack of family/husband support. 9.45\% women revealed of using emergency contraceptive pills 1-2 times per week as a substitute for regular contraceptives. - Đer the counter availability and easy to use" were cited as the preferred reasons but they were unaware of its effectiveness and possible side-effects after repeated use. $26.67 \%$ participants revealed of getting their pregnancies terminated without informing their husbands or taking oral abortifacients during pregnancy because of their inability to visit any health facility for termination as they were - $\mathbb{N}$ t allowed to leave the house". In case of husband's disapproval, the help of females in the neighbor-hood and maternal family was sought. One participant confirmed the use of birth control pills without informing her husband or other family members. Only 32.65\%women revealed of ever using intrauterine devices and 7\% medium term contraceptive tools. While 64\% woman experienced no problem another reported -bakache and difficulties in doing house work" after putting IUD.

\section{Knowledge, Attitude and Use of Modern Family Planning}

Awareness on family planning (FP) was almost universal with 98 percent of respondents confirming being aware. The main source of information or messages on FP was through the health workers (74.8 percent). Other sources are as indicated in the table below.

\begin{tabular}{|l|c|}
\hline $\begin{array}{l}\text { Characteristics } \\
\text { Source of information on FP } \mathbf{( N = 6 0 0 )}\end{array}$ & $\mathbf{( \% )}$ \\
\hline Health care workers & $74.70 \%$ \\
\hline Radio & $45.90 \%$ \\
\hline Friends and Kin & $26.20 \%$ \\
\hline TV & $16.40 \%$ \\
\hline Others & $12.80 \%$ \\
\hline \multicolumn{2}{|c|}{} \\
\hline Yes Know any specific $\operatorname{method}(\mathbf{N}=\mathbf{4 8 5})$ \\
\hline No & $80.80 \%$ \\
\hline \multicolumn{2}{|c|}{$19.20 \%$} \\
\hline Pills & $66.20 \%$ \\
\hline Injections & $64.40 \%$ \\
\hline Male condoms & $25.50 \%$ \\
\hline Implants & $15.10 \%$ \\
\hline Others & $17.60 \%$ \\
\hline
\end{tabular}

The pills and injections were the most widely known among study participants. A majority of the respondents (61.6\%) approved use of these methods. Reasons given for approval were diverse. Most of them (62.3\%) believed use of modern contraception helps to maintain standards of living, $45.3 \%$ indicated that it limits family and reduces expenditure, 25.5
$\%$ said it makes families small and happy, while 6.6 percent reported that it protects mother's health. Among the 19.2 percent of all respondents who did not approve use of modern FP, a majority (98.4 \%) feared harmful side effects. Fifty percent of all the participants had or their partner had ever used modern FP methods with the most commonly used options being injection (66.2\%), pills (64.4\%), and male condom (25.5\%). The long acting and permanent methods which were least known were similarly least used.

Variousfactors considered before choosing a particular method were given by the study subjects. Approval by partner (40.6\%), side effects (35.8\%), and accessibility (26.4\%) were the major considerations.

Other factors considered were acceptability of the method (18.4\%), convenience in using (14.6\%) and cost (13.7\%). Approval by friends (2.8 \%) and knowledge on the methods (9\%) were considered least in this group.

The current use of modern FP among all the respondents in the study was low (32.3\%). On sources of modern contraception, a majority (92.1\%) of those who had ever used got this service at the health facility.

\section{Role of Psychosocial Factors in Use of Modern Family Planning Methods}

Assessment of socio-cultural factors, measured on a likert scale, revealed that on average, the respondents who had ever used modern FP methods reported that cultural and religious beliefs, suggestions and approval from friends, and village talk did not influence their decision to use.

Neither did they think that traditional methods were better. However, they agreed that approval from their partners influenced their decision, and that choice of a contraceptive method was a couple's responsibility. $79 \%$ of the respondents who had ever used modern FP confirmed having discussed the choice and use with their partner, and many revealed that their partners were supportive. $95 \%$ of those who did not have discussions with their partners indicated that their partners had no knowledge of their use of these methods. The injection was the preferred method in this group.

Table Views on influence of socio-cultural factors on use of FP methods

\begin{tabular}{|c|c|c|c|}
\hline View & Agree & Neutral & Disagree \\
\hline Cultural beliefs & 35.4 & 6.4 & 68.2 \\
\hline Religious beliefs & 18.4 & 8.9 & 72.7 \\
\hline Friends approval & 44.3 & 14.6 & 41.1 \\
\hline Rumors/ village talk & 38.5 & 25.4 & 36.1 \\
\hline Partner approval & 51.4 & 28.6 & 30 \\
\hline Prefer traditional method & 8.4 & 12.4 & 79.2 \\
\hline Partners to choose method jointly & 71.2 & 11.4 & 17.4 \\
\hline
\end{tabular}

Discussion of family planning with partner was positively associated with current use of contraception. This finding is in line with other studies (Oni \& McCarthy, 1991; Salway, 1994). 
International Journal of Science and Research (IJSR)

ISSN (Online): 2319-7064

Index Copernicus Value (2013): 6.14 | Impact Factor (2015): 6.391

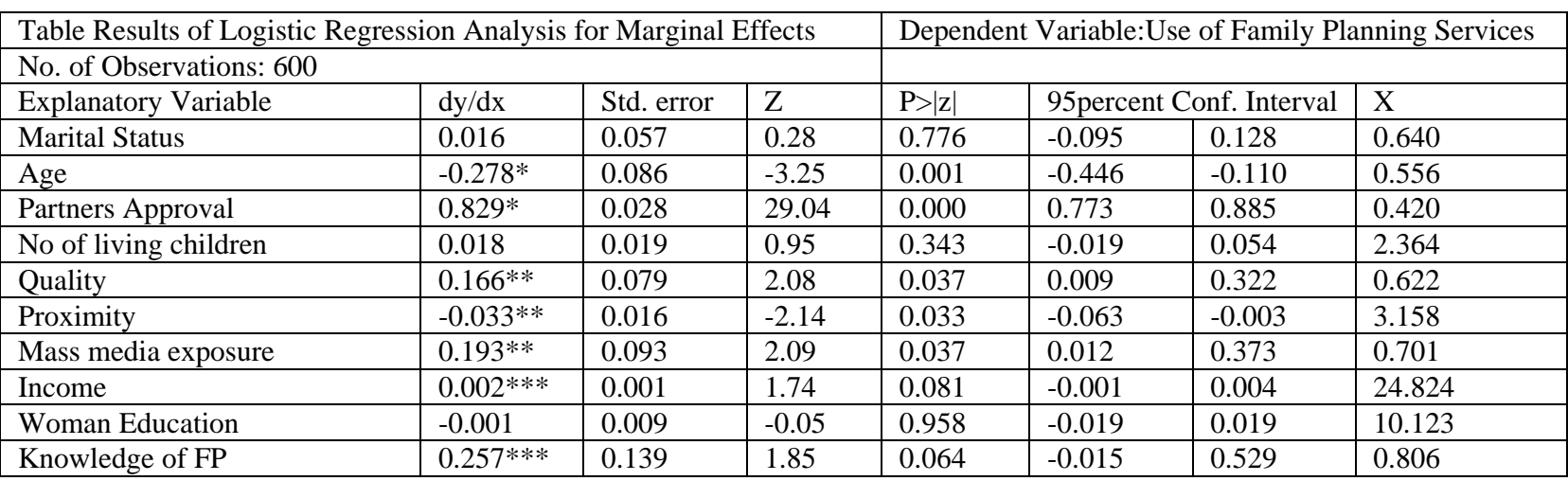

As presented in the above table, all the explanatory variables had coefficients with expected signs except woman education, which was however shown to negatively influence the use of family planning. The coefficient of woman education was, however, not statistically significant at 1 percent as well as 5 percent or 10 percent level of significance. Seven variables, namely marital status of the woman, partner's approval, number of living children, quality of family planning services, friendliness of family planning services providers, proximity to the provider, income of the woman and knowledge of woman on family planning services had coefficients with positive signs that they increase the likelihood of the respondent using family planning services. On the other hand, age of the woman, proximity to the provider and education level of the woman had negative coefficients. The coefficients of age and partner's approval were statistically significant at 1 percent whereas the coefficients of quality of family planning services, proximity to the provider and friendly staff at facility were statistically significant at 5 percent. On the other hand, the coefficients of income and knowledge of family planning were statistically significant at 10 percent level. Marital status and number of living children had coefficients that were not statistically significant at 1 percent as well as 5 percent and 10 percent. The most important determinant of the likelihood of respondents in the slums using family planning services was partner's approval, whose marginal effect was 0.83 . This means that the probability of a respondent using family planning services was 83 percent where consent from partner was granted compared to where no consent was granted. The significance of this could be attributed to the fact that for a woman to use family planning services, partner's approval was critical. Otherwise if found using without the consent of partner it could be misinterpreted, thereby causing misunderstanding in a marriage.

Knowledge of family planning services was found to be the third most important determinant of likelihood of using family planning services with a marginal effect of 0.26 . The likelihood of using family planning services would be 26 percent higher for woman with knowledge of family planning services than those without. This clearly suggests that for increased uptake of family planning services, promotion that facilitates awareness about the available family planning services and their possible side effects and benefits is paramount. Friendliness of family planning staff had a marginal effect of 0.19 , implying that the likelihood of respondents using family planning services was 19 percent higher if family planning staff was friendly than when they were not. The significance of this determinant could be explained by the fact that provision of certain types of family planning services requires performance of some procedures by the person administering the services, for example injectables, hormone releasing implants and use of IUD. With regard to quality of family planning services, the marginal effect was 0.17 . This implies that the probability of a woman using family planning services was 17 percent higher for respondents who perceived the services to be of high quality than for those who perceived otherwise. The positive impact of quality could be attributed to the fact that in the process of making a decision on using family planning services, perceived quality of the service is given a high consideration as supported by theory whereby taste and preference is an important factor in making demand decision. Proximity to family planning services provider had a marginal effect of negative 0.03, implying that the further away from the family planning services provider, the lower the likelihood of seeking the services by 3.3 percent. The negative impact of distance from the service provider could be attributed to the fact that when the provider is far away from the woman, there is bound to be some imbedded costs in terms of transport and transaction costs as well as waiting and travelling time, which may discourage a person from seeking the services. The last statistically significant variable was income, which had a marginal effect of 0.002, implying that an increase in average income of a woman by Kshs. 1,000 increased the likelihood of using family planning services by 2 percent. Marital status and number of living children had each a marginal effect of about 0.02, although they were statistically insignificant at 1 percent, 5 percent and 10 percent. The positive influence of marital status on the likelihood of using family planning services was attributed to the fact that couples might decide to postpone raising children by resorting to use of family planning services. The value of the marginal effect meant that a married woman is 2 percent more likely to use family planning services than a single woman.

Finally, the positive influence of the number of living children on the likelihood of using family planning services could be attributed to the woman's desire for children having been satisfied.

\section{Conclusion and Recommendation}

\subsection{Conclusion}

The results of the study have shown that clients chose family planning methods basing on few options given as most of 


\section{International Journal of Science and Research (IJSR) \\ ISSN (Online): 2319-7064}

Index Copernicus Value (2013): 6.14 | Impact Factor (2015): 6.391

health centers' family planning providers sampled were biased towards the three most commonly used methods, depoprovera, pills and condoms respectively. The low utilization of modern contraception despite a near universal awareness through various forums confirms that the women need more knowledge on FP methods that will focus on available options and their effects on health. Lack of adequate knowledge is confirmed by the few options that are known and ever used by the women, the fear of side effects as a major consideration when choosing a method and as barrier to use among those who have never used. Partner communication is also crucial in adopting a birth control option as it plays a major role while choosing a method. Women who discussed choice and use of contraceptive method were more likely to use compared to those who did not.

The importance of husband-wife communication in relation to fertility decision making is also emphasized by these findings. Tigrai's society is largely male-dominated, even with regard to female reproductive health, so men's involvement in family planning can therefore hardly be over-emphasized. One of the crucial factors which have hindered successful implementation of the family planning program in Tigrai is minimal male involvement.

\subsection{Recommendations}

- The study recommends that reproductive health programs need to intensify efforts in improving women's knowledge of modern FP methods. They should also encourage constructive partner communication and engagement in order to increase modern FP uptake.

- There is also need to re-evaluate the current integrated maternal child health and family planning services to directly, actively and effectively accommodate male partners. Further research into the male partner views on family planning; psychosocial and cultural determinants of non-use; and barriers to the use of modern contraceptive methods among both men and women is proposed.

- The family planning program at national level in conjunction with the woreda Health Offices should intensify supervision of family planning activities to ensure that providers are performing according to the set standards of family planning.

- Health centers should be provided with the National Reproductive Health (NRH) service delivery guidelines and policy to be used as a basis of their family planning service provision. In charge of health center should ensure that Ethiopian NRH and policy handbooks are always available in the FP clinic for easy access.

- Respondent's approval of family planning clearly stands out as the most important predictor of current use of contraception. The Ethiopian National Family Planning Program should intensify not only its information, education and communication programs on family planning to cover and adjust them to suit local conditions.

\section{References}

[1] FDRE, MoH, (2011). National Guideline for Family Planning Services in Ethiopia. Federal Democratic Republic of Ethiopia Ministry of Health, Oct 2011.
[2] Ha, B. T., R. Jayasuriya, et al. (2005). "Predictors of men's acceptance of modern contraceptive practice: study in rural Vietnam." Health EducBehav 32(6): 73850.

[3] Oni S. B., B. G. (1991). "Male involvement in family planning in Turkey." World Health Forum 19(1): 76-8.

[4] Saha, K. B., N. Singh, et al. (2007). "Male involvement in reproductive health among scheduled tribe: experience from Khairwars of central India." Rural Remote Health 7(2): 605.

[5] Salway K. B., N. (1994). "Male involvement in reproductive health among scheduled tribe: experience from Khairwars of central India." Rural Remote Health7(2): 605

[6] Toure, L (1996) Male Involvement in family planning, A review of Selected Program initiatives in Africa. Academy for Educational Development, Washington DC, pp4-7 